Departamento de Anatomia Descritiva dos Animais Domésticos lirctor: Prof. Dr. M. Barros Erhart

\title{
CONTRIBUIÇÃO PARA O ESTUDO \\ DAS CARTILAGINES CORNICULATA (SANTORINI) \\ E CUNEIFORMIS (WRISBERGI) NA LARINGE DE SUS SCROFA DOMESTICA $\left(^{*}\right)$
}

(CONTRIBUTION TO THE STUDY OF THE CARTILAGINES CORNICULATA

(SANTORINI) AND CUNEIFORMIS (WRISBERGI) IN THE LARYNX OF SUS SCROFA DOMESTICA)

\section{Barros Erhart}

2 istamnas (4 figuras)

O estudo das cartilagens acessórias da laringe do "Sus scrofa domestica", merece revisão, dada a discordância verificada nas descrições dos tratados de anatomia veterinária, assim como nas referências muito vagas encontradas nos raros trabalhos especializados, que focalizaram a disposição das referidas cartilagens.

As cartilagens acessórias habitualmente descritas na laringe dos mamíferos domésticos são: a cartilago cuneiformis (Wrisbergi ou Morgagni) colocada em plena espessura da prega ariepiglótica, e a "cartilago corniculata" (Santorini) que está localizada no ápice da aritenóide; é ainda encontrado na laringe de alguns mamíferos, inclusive na do porco, um núcleo cartilagíneo, entre os ângulos dorsomediais das aritenóides, denominado por SYIMINGTON c. interaritenoidéia, por FRANCK simplesmente de c. sesamoidéia e por LEYH, ElLENBERGER \& BAUM de c. interarticular.

No que diz respeito a esta última, cuidadoso estudo foi feito por FAvilli que, não só focalizou a situação e estrutura, assim como ar provável função desta cartilagem no Sus scrofa, chegando o A. às seguintes conclusōes: que dos processos mediais das aritenóides se elevam sempre duas apófises cilíndricas de cartilagem elástica, que tocando-se na linha média constituem um arco, em cujo ápice está um nódulo de cartilagem hialina denominado interaritenóideo. Este nódulo estudado por SYimington nos marsupiais, pela sua posição, pode ser homologado a procricóide posterior estudada por DuBoIs no ornitorrinco; para o porco esta homologia não é confirmada, porque sempre o meio de união colocado entre as formações é representado por cartilagem elástica.

22-28/1/19.8. Auresentado no IV Congresso Brasiluiru do Medicina Veterinciria, Rio de Janeiro, 
As aritenóides no porco apresentam ainda a particularidade de se unirem pelas suas extremidades livres, de modo a permitir ao $\mathbf{A}$. pensar num sistema aritenóideo, impar, como disposição normal dêsse animal.

A forma, a posição e a estrutura do trato de união entre as apófises basais do sistema aritenóideo, encontram sua justificativa na função que devem exercer, em relação aos movimentos imprimidos pelos diversos músculos aos dois ramos das cartilagens. 0 núcleo de cartilagem hialina, isto é, a cartilagem interaritenoidéia, representaria a "chave" do arco formado pelos processos dorsomediais, aos quais está reunida por cartilagem elástica.

Como o objetivo precípuo do trabalho de FAviLli cra estudar a c. interaritenoidéia, não entra em pormenores sôbre as demais cartilagens acessórias, lembrando apenas que, a cartilagem cuneiforme de Wrisberg se apresenta como formação achatada localizada em plena espessura da prega ariepiglótica. No decurso da exposição não é encontrada referência à cartilagem corniculada, tanto assim que, ao descrever a aritenóide, considera como particularidade dessa cartilagem, no porco, o se apresentar unida à homóloga hétero-lateral pela sua extremidade livre.

Negus estudando a função da cartilagem de Santorini, refere que esta é muito longa e desenvolvida no porco, e Citelli em trabalho sôbre a cartilagem supracricoidéia no homem, faz referência aos nódulos cartilagíneos, considerando a c. cuneiforme (Morgagni) como presente e desenvolvida em muitos mamíferos, ao passo que a c. corniculada (Santorini) pode faltar em muitos animais.

Compulsando os tratados de anatomia veterinária verifica-se que a existência das cartilagens acessórias é as mais das vêzes, apenas lembrada, sendo que, alguns compêndios pecam pela completa omissão de dados.

Assim Bourdelle (p. 178), ao descrever a aritenóide, chama atenção sôbre a presença da incisura localizada na extremidade superior da cartilagem, que a divide em duas porções desiguais, sendo a apófise interna, resultante da divisão, soldada à homóloga oposta. Não há referência às cartilagens acessórias.

LESBRE (p. 40), nada escreve sôbre as formações acessórias da laringe do porco, lembrando sòmente a presença da incisura na extremidade da c. aritenóide.

Caradonna in Zimmerl (p. 648), ao tratar do comportamento geral da laringe no porco, diz: quanto à constituição anatômica devese observar: a) ao esqueleto cartilagíneo descrito para os Eqüinos acrescentem-se duas cartilagens postas ao lado das aritenóides, de for- 
ma cilindrica, achatadas lateralmente e compreendidas na espessura da prega ariepiglótica, denominadas cartilagens cuneiformes ou de Wrisberg.

Segundo êste A., as aritenóides são longas e soldadas entre si na proximidade do ápice formando uma espécie de goteira profunda.

BRUNI (p. 129), sòmente faz descrição sumária da c. aritenóide, considerando-a muito alta e reunida à oposta pela ápice.

Martin (p. 68) escreve: aos desenvolvidos processos das aritenóides estão apensos robustas cartilagens corniculadas, as quais se subdividem na extremidade; o processo medial, mais longo, reune-se ao homólogo oposto, formando goteira, por intermédio de formação elástica. O processo lateral é menor e ponteagudo, constituindo a base de segunda prega mucosa encontrada no ápice da aritenóide. Assim como no cavalo e boi, no porco é encontrado o ligamentum arycorniculatum, o qual se extende da aritenóide para a c. corniculada segundo Franzmann. As pregas ariepiglóticas, bem desenvolvidas, envolvem a aritenóide.

Ellenberger \& BaUm (p. 447), mencionam a localizaçāo de pequena cartilagem elástica cạrtilago corniculata (Santorini), sôbre o ângulo nasodorsal da aritenóide; aquela, bem desenvolvida no cavalo, no cão e no porco, apresenta-se neste último bifurcada na extremidade livre. Mais adiante (p. 478): a cartilago cuneiformis (Wrisbergi) falta nos ruminantes, no porco e no gato, sendo no cão muito desenvolvida e aplicada à aritenóide; (p. 512) : a cartilagem corniculada, no porco, apresenta o ápice bifurcado, sendo o processo medial resultante da bifurcação, mais robusto e soldado ao homólogo hétero-lateral; como resultado desta reunião na linha média constitui-se goteira ímpar. O processo lateral é menor e se apresenta em forma de estilete. Negam, portanto, êstes AA. a existência da c. cuneiforme no porco.

Depois de apresentados os resultados pessoais, serão confrontados os nossos achados com os dos AA.

O material de estudo compõe-se de 6 laringes, sendo 4 de animais adultos e 2 de fetos de têrmo. A pós cuidadosa dissecção a fresco, para permitir o isolamento in totum de ambas cartilagens aritenóides e das pregas ariepiglóticas, as 4 primeiras peças foram fixadas em formol, coradas eletivamente pelo verde metila e, finalmente, diafanizadas pelo método de Spalteholz. As duas outras, de fetos, reduziramse a cortes tranversais, seriados, de $10 \mathrm{k}$, corados pela hematoxilinaeosina. 
As peças diafanizadas permitem perfeita visualização da aritenóide, assim como do núcleo cartilagíneo contido na prega epiglótica,

A cartilagem aritenóide no porco, além das características morfológicas próprias dos outros mamíferos, apresenta, de acôrdo com a descrição de Favilli, Caradonna, Bruni e Bourdelle, o ápice longo e encurvado reunido ao do lado oposto, formando ao nive! da soldadura, goteira profunda voltada dorsalmente. Este ápice, longo e encurvado, si bem que fazendo corpo com a aritenóide, parece-nos, deve ser considerado como representando a c. corniculada, muito desenvolvida e reunida à aritenóide, de modo a não permitir identificá-la como formação independente. Fsta afirmativa tem como base a apreciação do desenvolvimento das cartilagens da laringe; ChiArugi (p. 291) considera, para o homem, a pequena c. corniculada como derivada do ápice da aritenóide e GöPPERT in HERTwIG considera como elementos primários do esqueleto da laringe, que atingem completo desenvolvimento, a c. aritenóide com a c. de Santorini, sendo que a parte mais oral da primeira fornecerá a cartilago corniculata (Santorini).

Entre os ângulos dorsomediais da aritenóide está localizada a c. sesamóide interaritenoidéia, presente em alguns mamíferos e cuidadosamente estudada, no porco, por FAVILLI, como foi referido no apanhado bibliográfico.

A cartilagem cuneiforme de Wrisberg, colocada em plena espessura da prega ariepiglótica, portanto lateralmente à aritenóide, aparece como lâmina achatada transversalmente, de forma uncinada, (Fig. 1). Mostra duas extremidades livres: a ventral, acompanha a face lateral da aritenóide, atingindo, em plena espessura da prega ariepiglótica, as proximidades do processo vocal; a dorsal, colocada lateralmente ao ápice da aritenóide e c. corniculada, constitui o arcabouço da característica prega mucosa lateral da laringe do porco. As bordas, em virtude da forma e posição da c. de Wrisberg, estão orientadas dorsal e ventralmente; a primeira, convexa e livre em tôda a extensão, ultrapassa dorso-oralmente a aritenóide; a segunda, côncava, está reunida pela porção média à aritenóide e à c. corniculada. As faces voltadas medial e lateralmente apresentam série de orificios, preenchidos por glândulas e revestidos pela mucosa nas peças íntegras.

A observação dos cortes da laringe permite verificar sem contestação que, nos fetos, a c. cuneiforme de Wrisberg não está reunida à aritenóide nem à c. corniculada em nenhum ponto, ao longo de sua localização em plena espessura da prega ariepiglótica (Fig. 3).

Esta localização da c. cuneiforme corresponde exatamente ao seu desenvolvimento, pois, em Chiarugi (p. 292) lê-se: as pregas membranosas ariepiglóticas são dependência da epiglote e contém rudi- 
mentos do primitivo esqueleto cartilagíneo, que dela derivam, representados, de cada lado, pela c. cuneiforme; GöPPERT por sua vez, considera como formação de desenvolvimento tardio, a epiglote com a c. cuneiforme, sendo que sùmente nos mamíferos é a epiglote encontrada como formação autônoma, nada tendo de comum com esta cartilagem, o processo epiglótico da cricóide encontrado nos Saurospsídeos. A cartilagem epiglótica adaptou-se, pela sua porção oral, à prega ariepiglótica; a parte basal possui, originalmente, dois processos que, ao desenvolver-se podem contornar o ádito laríngeo e, finalmente individualizar-se como c. cuneiforme. A permanência de tecido conjuntivo reunindo ambas cartilagens, observado nos fetos humanos de 29 semanas, demonstra a origem da c. de Wrisberg como derivado do esqueleto epiglótico.

A independência da cartilagem contida em plena espessura da prega ariepiglótica, no que diz respeito a aritenóide, e, por outro lado, a presença de tecido conjuntivo, ligando-a à epiglote, (Fig. 2) nos levam, sem dúvida, a considerar a formação cartilagínea contida na prega, como sendo a cartilagem cuneiforme de Wrisberg.

No que tange à c. corniculada de Santorini, nos cortes examinados, apresenta-se elá reunida ao ápice da aritenóide não permitindo se conclua pela existência como formação independente em fetos de têrmo, (Fig. 3). Entretanto, sabenclo-se que esta cartilagem tira sua origem da divisão do ápice da aritenóide, como já foi referido, e, mais que sua estrutura é de cartilagem elástica, (Fig. 4), contrastando com a cartilagem hialina da aritenóide, por último, verificando-se a presença de formaçōes glandulares $\mathrm{cm}$ plena espessura do prolongamento da aritenóide, não parece conclusão forçada admitir-se, se trate, realmente, da cartilago corniculata (Santorini).

Estudo analítico de confronto, das observações que colhemos mediante exame das lâminas e peças provenientes de animais adultos e as descrições oferecidas pelos vários AA., mostra não só profunda discordância de opinião entre êstes, como também com o próprio ponto de vista que assentamos.

De um lado, CARDonNa e FAviLli fazem referência à presença da c. de Wrisberg incluida na prega ariepiglótica, mas nada mencionam sôbre a particularidade dessa formação se apresentar reunida, nos animais adultos, à aritenóide. Êstes AA. ao descreverem a aritenóide admitem como fazendo parte dessa estrutura, o prolongamento longo e encurvado, soldado ao do lado oposto, que limita dorsalmente o ádito laríngeo; êste prolongamento, segundo nossas observaçōes, deve ser considerado como a cartilagem corniculada de Santorini. 
De outro lado, Martin e Ellenberger \& BaUm consideram a cartilagem elástica aplicada à porção apical da aritnoide, como a c. de Santorini, portanto, ao descreverem a aritenóide, admitem as duas porções, resultantes da divisão da extremidade livre, como pertencentes àquela formação. Não é possível compreender qual a razão que levou êstes AA. a descrever, o processo lateral da estrutura cartilagínea, que está incluida na prega ariepiglótica, no porco, com disposição idêntica àquela encontrada no cão, como dependência da c. corniculada, quando tudo indica, não só pela situação e morfologia, assim como, pelo desenvolvimento, estarmos na presença da c. cuneiforme de Wrisberg, fato êste claramente admitido por MARTIN e ELLENBERGER \& BAUM para o cão.

Para finalizar LESBRE e BOURDELle, silenciando completamente. a respeito das cartilagens acessórias, consideram a porção apical da aritenóide, dividida por profunda incisura em duas apófises: lateral e medial. Estes dois processos, a nosso juizo, nada mais seriam que as porções livres das cartilagens de Santorini e Wrisberg.

\section{CONCLUSÕES}

Como resultado do exame das peças diafanizadas, dos cortes seriados e da literatura pode-se concluir que:

1) Há discordância na descrição dos diversos AA. quando focalizam as cartilagens acessórias da laringe do porco.

2) A laringe do porco apresenta, em plena espessura da prega ariepiglótica, a cartilago cuneiformis (Wrisbergi). Esta cartilagem bem desenvolvida, no animal adulto, está reunida pela borda ventral à c. aritenóide e à c. corniculada; nos fetos conserva completa independência no interior da referida prega.

3) A cartilago corniculata (Santorini) colocada no ápice da aritenóide, como de hábito, está ìntimamente reunida à esta última, a ponto de não ser possível identificá-la como formação isolada. Entretanto, sabendo-se que esta cartilagem tira sua origem da divisão do ápice da aritenóide, e, mais que sua estrutura é de cartilagem elástica, contrastando com a cartilagem hialina da aritenóide, deve-se considerá-la como presente na laringe do Sus scrofa domestica.

\section{SUMMARY}

This study was originated by the discordance of discriptions presented by several AA. upon the cuneiform (Wrisberg) and corniculate (Santorini) cartilages, in the pig. 
About this subject BOURDELLE, LESBRE and BRUNI offer us short discriptions of the laryngeal cartilages without mentioning the acessories ones.

FAvilli and CARADONNA mentions the existence of the Wrisberg cartilage included in the ari-epiglottic fold but when describing the arytenoid cartilage they accept as a part of this structure the long and curved prolongacion soldered to that of the opposite side, which bounds the aditus laryngis dorsally.

Finally MARTIN and ELLERBERGER-BAUM admit that the elastic cartilage applied to the apical portion of the arytenoid is the Santorini cartilage, and thercfore when speaking of this formation they describe both parts, resulting from the division of the free extremity, as dependant of this cartilage.

Larynges from 4 adult animals and 2 fetuses at birth time were used in this study. The pieces of adult animals were stained with methylgreen and diaphanised by the Spalteholz method. The larynges of fetuses were sectioned serially at 10 microns in a transverse plane, and stained with hematoxilin-eosin.

Spalteholz method made possible the observation of morpholosical details in the arytenoids, cuneiform and corniculate cartilages as well as in the cartilagineous nucleus always present between the medial angles of the arytenoids. The slides clear up some doubtful points relatively to the behaviour of the cartilages. Technics employed and the appreciation of literature permitted us to come to the following conclusions:

1) There is a desagreement on the several descriptions of the accessory cartilages concerning the larynx of the pig.

2) The larynx of this animal, situated within the aryepiglottic fold, presents, the cartilago cuneiformis (Wrisbergi). This cartilage, well developed in the adult animal, is connected by the ventral border to the arytenoid and corniculate ones; in fetuses it presents complete independence in the interior of the mentionated fold.

3) The cartilago corniculata (Santorini) usually situated in the apice of the arytenoid, is closely connected to this last and therefore, it becomes impossible to identify it as an isolated formation. However, being aware abouth the origin of this cartilage, from the division of the arytenoid extremity, and moreover knowing that its structure is elastic, contrasting with the arytenoid cartilage which is hyaline, we have to admit that this cartilage exists in the larynx of $S u s$ scrofa domestica. 


\section{BIBLIOGRAFIA}

Bourdelle, E. - 1920 - "in" Montanè - Bourdelle. Anatomie régionale des animaux domestiques. 3: porc. Paris, Baillière et fils.

BRUNi, A. C. - 1947 - "in” Bruni - Zimmerl. Anatomia degli animali domestici. 2. Milano, Francesco Vallardi.

Caradona, G. B. - 1930 - "in" Zimmerl, U. Trattato di Anatomia Veterinaria. 2. Milano, Francesco Vallardi

Chiarugi, G. - 1940 - Trattatto di Embriologia, 4 (1). Milano, Soc. Ed. Libraria.

Crtellı, J. - 1904 - Sull'esistenza di una cartilagine sopracricoidea nell'uomo e sulla sua importanza morfologica. Anat. Anz., 24: 289-296.

Ellemberger, W. - BaUM, H. - 1932 - Handbuch der vergleichenden Anatomie der Haustiere. 17 Aufl. Berlin, Julius Springer.

Favili, N. - 1927 - Contributto allo studio della cosidetta "cartilagine sesamoide interaritnoidea" in Sus scrofa. Arch. It. Anat. Emb., 21: 189-200.

GÖPPERT, E. - 1906 - "in" Hertwig. Handbuch der vergleichenden und experimentellen Entwickelungslchre der Wirbeltiere. 2 (1): 86-96. Jena, Gustav Fischer.

Lesbre, F. X. - 1923 - Précis d'Anatomie comparée des animaux domestiques. 2. Paris, J. B. Baillière et fils.

Martin, P. - 1923 - Lehrbuch der Anatomie der Haustiere. 4. 2 Auf. Stuttgart, Schickhardt \& Ebner.

Negus, V. E. - 1929 - Function of the cartilages of Santorini. J. Anat., 63: 430-3.

\section{EXPLICAÇÃO DAS FIGURAS}

Fig. 1 - Desenho das cartilagens aritenóide, cuneiforme, e corniculada, reproduzido da peça diafanizada.

Fig. 2 - Corte transverso da laringe de feto, a secção ainda não atingiu todo contôrno do adito laríngeo, nota-se tecido conjuntivo como meio de união entre a epiglote e a c. cuneiforme. (Col. hematoxilina-eosina).

Fig. 3 - Corte transverso da laringe de feto, as cc. corniculadas mantem-se independentes na linha média, a c. suneiforme aparce $\mathrm{cm}$ plena espessura da prega ariepiglótica. (Col. hematoxilina-eosina).

Fig. 4 - Corte transverso da laringe de feto, as cc. corniculadas egtão reunidas na linha média. Típica cartilagen elástica nas formaçōes cartilagíneas acessórias. (Col. hematoxilina-cosina). 


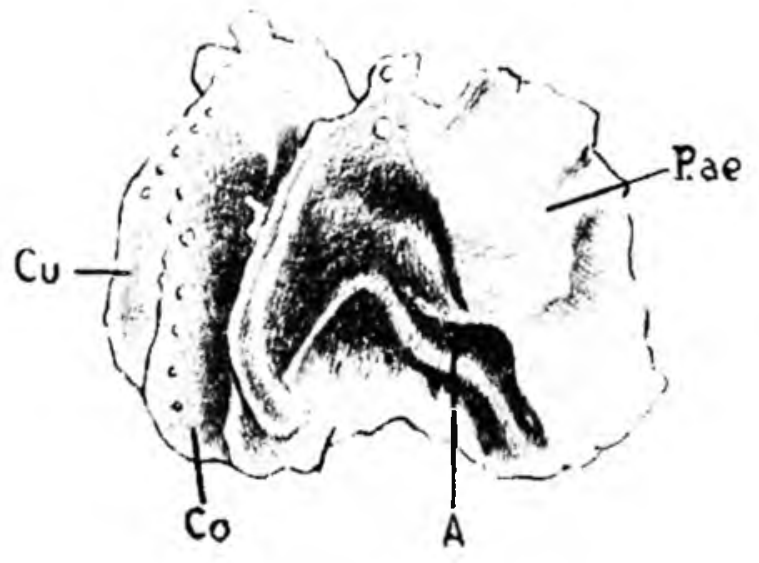

Fir. 1

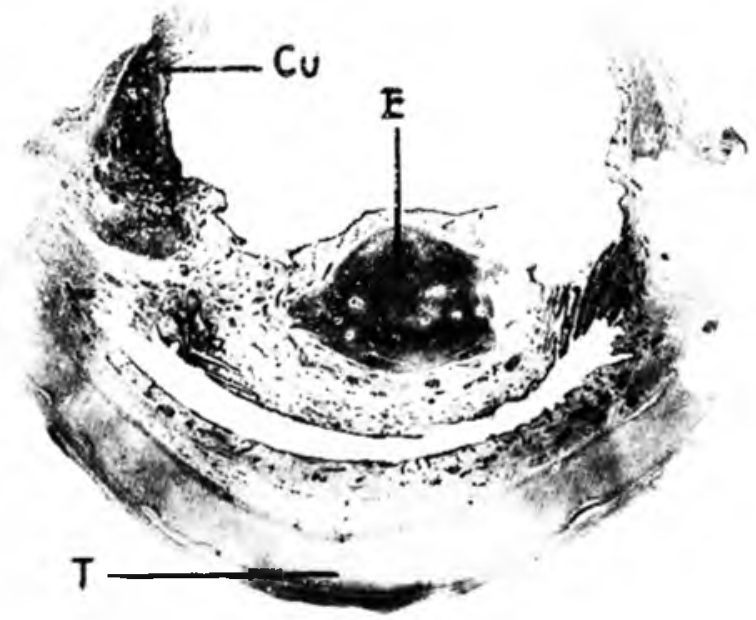

F'ig. 2 


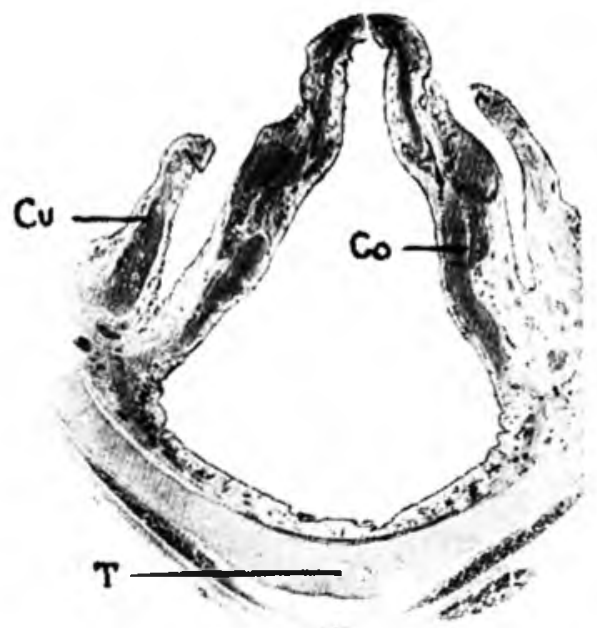

Fig. 3

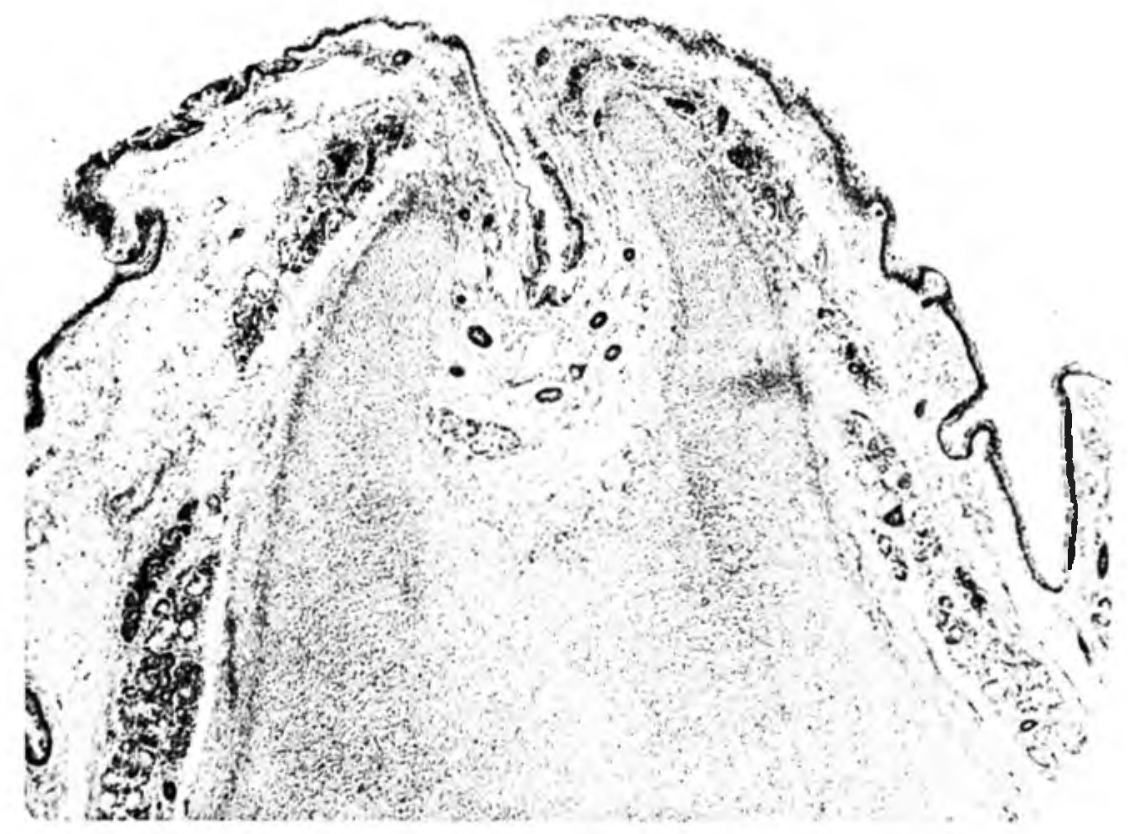

Fir. 4 